\title{
Correction to: Dynamics of Neural Networks
}

\section{Correction to:}

\section{J. A. M. van Putten, Dynamics of Neural Networks, https://doi.org/10.1007/978-3-662-61184-5}

In the original version of the book, the following corrections have been incorporated:

1. In Chap. 4, Fig. 4.3 has been updated.

2. Links to electronic supplementary material in Chaps. 1, 2, 4, 5, 6, 7, 8, 9 have been included.

The book and the chapters have been updated with the changes.

\footnotetext{
The updated version of these chapters can be found at https://doi.org/10.1007/978-3-662-61184-5_1, https://doi.org/10.1007/978-3-662-61184-5_2, https://doi.org/10.1007/978-3-662-61184-5_4, https://doi.org/10.1007/978-3-662-61184-5_5, https://doi.org/10.1007/978-3-662-61184-5_6, https://doi.org/10.1007/978-3-662-61184-5_7, https://doi.org/10.1007/978-3-662-61184-5_8, https://doi.org/10.1007/978-3-662-61184-5_9 and https://doi.org/10.1007/978-3-662-61184-5 